\title{
Correction to: Long-Term Health-Related Quality of Life (HRQoL) After Redo-Fundoplication
}

\author{
Antti J. Kivelä ${ }^{1} \cdot$ Juha Kauppi $^{2} \cdot$ Jari Räsänen $^{2} \cdot$ Anna But $^{3} \cdot$ Harri Sintonen $^{4} \cdot$ Jaana Vironen $^{1}$ • \\ Olli Kruuna ${ }^{1} \cdot$ Tom Scheinin ${ }^{1}$
}

Correction to: World J Surg

https://doi.org/10.1007/s00268-021-05954-3

The following statement was missing from the original online version of the article:

Antti J. Kivelä and Juha Kauppi are co-first authors.
The original article has been updated.

Publisher's Note Springer Nature remains neutral with regard to jurisdictional claims in published maps and institutional affiliations.

The original article can be found online at https://doi.org/10.1007/ s00268-021-05954-3.

Antti J. Kivelä

antti.kivela@hus.fi

1 Department of GI Surgery, Abdominal Centre, Helsinki University Hospital and Helsinki University, Jorvi Hospital, Turuntie 150, P.O. Box 800, 00029 Espoo, Helsinki, HUS, Finland

2 Chief of Division-Department of General Thoracic and Esophageal Surgery, Lung and Heart Center, Helsinki University Hospital and Helsinki University, Helsinki, Finland

3 University of Helsinki, Helsinki, Finland

4 Department of Public Health, Faculty of Medicine, University of Helsinki, Helsinki, Finland 